\title{
NEIGHBORHOODS OF A NEW CLASS OF P-VALENTLY STARLIKE FUNCTIONS WITH NEGATIVE COEFFICIENTS
}

\author{
MUHAMMET KAMALI
}

Abstract. A certain subclass $T^{m}(n, p, \alpha, \lambda)$ of p-valently starlike functions in the unit disk is introduced. By making use of the familiar concept of neigborhoods of p-valent functions, the author proves coefficient bounds and distortion inequalities, and associated inclusion relations for the $(n, \delta)$ - neighborhoods of functions belonging to the class $T^{m}(n, p, \alpha, \lambda)$, which is defined by means of a certain nonhomogeneous Cauchy-Euler differential equation.

Mathematics subject classification (2000): 30C45.

Key words and phrases: p-valently starlike function, nonhomogeneous Cauchy-Euler differential equation, $(n, \delta)$ - neighborhood, distortion inequality, convex functions.

\section{REFERENCES}

[1] O. ALtintAŞ, On a subclass of certain starlike functions with negative coefficients, Math. Japon., 36, (1991), 489-495.

[2] O. Altintaş, H. IRMAK AND H. M. SRIVASTAVA, Fractional calculus and certain starlike functions with negative coefficients, Comput. Math. Appl., 30, (2) (1995), 9-15.

[3] O. Altintaş, S. Owa, Neighborhoods of certain analytic functions with negative coefficients, Internat. J. Math. And Math. Sci., 19, (1996), 797-800.

[4] O. AltinTAŞ, Ö. ÖZKAN AND H. M. SRIVASTAVA, Neighborhoods of class of analytic functions with negative coefficients, Appl. Math. Lett., 13, (3) (2000), 63-67.

[5] O. AltintaŞ, Ö. ÖZKAN AND H. M. SRIVASTAVA, Neighborhoods of a certain family of multivalent functions with negative coefficients, Comput. Math. Appl., 47, (10)-(11) (2004), 1667-1672.

[6] ST. RuscheweYH, Neigborhoods of univalent functions, Proc. Amer. Math. Soc., 81 (1981), 521-527.

[7] A. W. Goodman, Univalent functions and nonanalytic curves, Proc. Amer. Math. Soc., 8, (1957), 598-601.

[8] G. S. Salagean, Subclasses of univalent functions, Lectures Notes in Math., Springer-Verlag, 1013, 362-372, (1983). 